\title{
Evaluation of the Energy Performance of the Amougdoul Wind Farm, Morocco
}

\author{
Asma Ezzaidi $^{1}$, Mustapha Elyaqouti ${ }^{2}$, Lahoussine Bouhouch ${ }^{3}$, Ahmed Ihlal $^{4}$ \\ ${ }_{1,2,3}$ ERTAIER, ESTA, BP 33/S, 80000 Agadir, Morocco \\ ${ }^{4}$ Laboratory of Materials and Renewable Energy, Faculty of science university Ibn Zohr Agadir, Morocco
}

\begin{tabular}{|c|c|}
\hline Article Info & ABSTRACT \\
\hline Article history: & This paper is concerned with the assessment of the the performance of the \\
\hline Received Nov 3, 2016 & Amougdoul wind farm. We have determined the Weibull parameters; namely \\
\hline Revised Jan 23, 2017 & estimated energy output by a wind turbine using two techniques: the useful \\
\hline Accepted Feb 6, 2017 & $\begin{array}{l}\text { power calculation method and the method based on the modeling of the } \\
\text { power curve, which is respectively } 134.5 \mathrm{~kW} \text { and } 194.19 \mathrm{KW} \text { corresponding }\end{array}$ \\
\hline Keyword: & $\begin{array}{l}\text { to } 27 \% \text { and } 39 \% \text { of the available wind energy, which confirm that the } \\
\text { conversion efficiency does not exceed } 40 \% \text {. }\end{array}$ \\
\hline
\end{tabular}

Distribution of weibull

Energy

Wind farm

Wind generators

Wind rose

Copyright $@ 2017$ Institute of Advanced Engineering and Science. All rights reserved.

\section{Corresponding Author:}

Asma Ezzaidi,

Electrical Engineering Department,

ESTA, BP 33/S, 80000 Agadir, Marocco.

Email: ezzaidi.asma@gmail.com

\section{INTRODUCTION}

Morocco, among other countries around the world, faces increasing needs of energy and limited conventional energy resources. The country relies heavily on energy imports. Furthermore, it is strongly affected by climate change (CC) effects and exhibits a strong vulnerability to global warming at different levels. Forests, agriculture, fishing, water supplies, and tourism are being among the most vulnerable ecosystems. For instance, Morocco, which is hosting COP22, signed the COP 21 Paris Agreement aiming at keeping in this century a global temperature rise well below $2^{\circ} \mathrm{C}$. For this concern, Morocco adopted a new green energy policy which will enable the country to benefit from its abundant potential in wind power estimated at $25000 \mathrm{MW}$. The actual installed capcity is around $1300 \mathrm{MW}$ and expected to be brought to 2000 MW by 2020.

The intergration of renewable energy resources is becoming nowadays a reality [1], [2]. Wind energy, offering lower costs than other enetrgy resources, has developed rapidly around the world [3], and has attracted a lot of attention recently because of its great benefits in reducing GHG emissions [4]. A wind turbine, commonly called thewind is a device which transforms a part of the kinetic energy of wind into mechanical energy available on a shaft and then into electrical energy via a generator (DFIG) [5].

Knowing that the energy efficiency of wind turbines and the outpout power are a function of wind speed, it's important for the wind industry to know the factors related to changes in wind speed, to optimize turbine design thus minimizing the costs of producing electricity which are a cost prediction tool for investors. Therefore, our investigations will contribute to the development of a tool aiming to support the decision for the competent authorities supervising the development of national energy resources to supply electricity and to better take advantage of the significant potential of wind resources in Morocco.

To address such issue, several studies were performed. In this way, Kasbadjimerzouk [6] processed 
two methods of the Weibull distribution: the graphical method and the iterative calculations of the moments. Two factors were calculated: the form factor, $k$ and the scale factor, $c$. These two factors will enable to assess the energetic potential available at a given location. Another example is that studied by Faida et al [7]. In their work, the authors modeled the wind frequency distribution using the Weibull distribution, and then they sized the wind farm. After that, they evaluated its wind potential so as to predict the produced electrical energy.

This study deals with the evaluation of the energy performance at the Amougdoul Wind farm. The Weibull parameters will be determined. The energy outpout of the wind turbines is evaluated using two techniques: the useful power calculation method and the method based on the modeling of the power curve

\section{CONTEXT AND INVESTIGATION PLATEFORM}

In this section, we will present the Amougdoul wind farm. The site (Coordintes: 31.413263, -9.802698) is located on one of the furthest western points of the central Atlantic coast of Morocco (Cap Sim). This wind farm enjoys access to the trade wind regime which is quite peculiar even though it is located more than $600 \mathrm{~km}$ north of the Saharan coast [8].

This park includes 71 wind asynchronous turbines, type GAMESA G52-850 [9], with $850 \mathrm{~kW}$ of nominal power. All the wind turbines are connected via an underground internal electrical network to MV $60 \mathrm{KV}$ national Grid. The park also includes a MV/HV transformer station for the evacuation of the energy using digital technology. The park was built within the framework of the national strategy aiming at promoting renewable energy to reach $1000 \mathrm{MW}$ in 2012.

Wind characteristics which we will use later in this study were collected every 10 min during the year 2012, on the turbines of the Amougdoul wind farm. These data are the wind speed, direction and power of the wind turbine GAMESA G52-850.

\section{ENERGY STUDY OF THE WIND FARM}

The first stage of our investigations, concerns energy study of the Amougdoul wind farm. Therefore, we have studied the characteristics of the wind which is a major factor in the production of wind energy. Indeed, to evaluate this energy production and financial viability of the wind farm under study, we will present the history and distribution of wind on the wind farm. However, winds vary differently depending on the day, season and year. The profile of this variation must be estimated in order to adapt the wind energy systems design to needs, which are also variable depending on the day, season or year. Daily variations of wind characteristics are determined by studying the evolutions of the speed and wind direction. The seasonal and annual variations of these characteristics are estimated respectively at monthly and yearly scales. This requires large data sets processing [6].

\section{MATHEMATICAL MODELING}

\subsection{Direct Statistical Processing of Wind Data}

Statistical processing of the data associated with the wind depends on the nature and number of measurements available. This pretreatment allows reducing the data volume. This method has the advantage of representing the observed data by a limited number of parameters, while providing valuable information to users of wind energy. Such information include, among others, fluctuations in wind speed allowing the determination of the wind potential of a given site to estimate wind energy that it can produce [10].

The expression (1) gives the average wind speed calculated from the arithmetic average of all readings of actual speed according to a frequent and regular sampling.

$$
V_{\text {moy }}=\frac{1}{N} \sum_{i=1}^{N} V_{i}
$$

where $V_{i}$ represents the average speed during a sampling period $\Delta t$.

The standard deviation of wind speeds is given by Equation (2). This is a criterion that measures the dispersion of wind speeds around its mean value. The speeds are grouped around an average speed when this standard deviation is lower. 


$$
\sigma=\sqrt{\frac{1}{N-1} \sum_{i=1}^{N}\left(V_{i}-V_{\text {moy }}\right)^{2}}
$$

\subsection{Modelisation of the Frequency Distribution of Wind Speed}

The main objective of this section is to find out a mathematical function representing the frequency distribution of wind speeds. This function is very useful for calculating the performance of a wind energy system at a given location, particularly where it is desired to estimate the wind power available at different altitude from those where the measurements are made.

\subsubsection{Weibull Distribution}

The Weibull distribution is used to translate the variation of wind speeds. It permits to characterize the frequency distribution of wind speeds over time to analyze the wind potential from a given location [11]. This distribution of the wind speed $V$ is defined by the probability density, $f(V)$, given by the following expression:

$$
f(V)=\left(\frac{k}{c}\right)\left(\frac{V}{c}\right)^{k-1} e^{\left(-\frac{V}{c}\right)^{k}}
$$

with firstly, the scale parameter, $c(\mathrm{~m} / \mathrm{s})$, informing us about the average wind speed, characterising the site and secondly the shape parameter, $k$ (unitless) indicating the character, more or less pointed of distribution [12].

\subsubsection{Determination of Average Wind Speed and its Standard Deviation}

Depending on the Weibull parameters, the average speed is given by the following Equation:

$$
V_{\text {moy }}=c \Gamma\left(1+\frac{1}{k}\right)
$$

where $\Gamma(x)$ is the Gamma function expressed by:

$$
\Gamma(x)=\int_{0}^{+\infty} t^{x-1} e^{-t} d t
$$

The expression of the standard deviation of the wind speed is given by the following Equation:

$$
\sigma=\sqrt{c^{2}\left[\Gamma\left(1+\frac{2}{k}\right)-\Gamma^{2}\left(1+\frac{1}{k}\right)\right]}
$$

\subsection{Methods Determining Weibull Parameters}

In order to determine the Weibull parameters $c$ and $k$, from statistical data of the wind, many techniques can be used [13]. Among these techniques, we retain that of least squares and that of standard deviation and average speed.

\subsubsection{Least Squares Technique (Ls)}

This method is often used to determine Weibull parameters, $c$ and $k$, by discretizing the function $f(V)$, in frequencies $f_{1}, f_{2}, f_{3}, \ldots, f_{n}$ and cumulative frequency, $p_{1}=f_{1}, p_{2}=p_{1}+f_{2}, \ldots, p_{n}=p_{n-1}+f_{n}$.

Considering the logarithms $x_{i}$ and $y_{i}$, such as: $x_{i}=\operatorname{Ln}\left(V_{i}\right)$ and $y_{i}=\operatorname{Ln}\left[-\operatorname{Ln}\left(1-p_{i}\right)\right]$, we get the Equation of a line $y=a x+b$, with coefficients $a$ and $b$ adjusted by linear regression. We access and, according to some writers [12], to parameters, $c$ and $k$, such that:

$$
k=a \text { and } c=e^{\left(-\frac{b}{a}\right)}
$$




\subsubsection{Technique of the Standard Deviation and Average Speed Sd}

In the case where there is only the average wind speed $V$, and the standard deviation $\sigma$, we can determine parameters $k$ and $c$ from the following formulations [13, 14]:

$$
k=\left(\frac{\sigma}{V}\right)^{-1.086} \text { and } c=\frac{V}{\Gamma\left(1+\frac{1}{k}\right)}
$$

with the Gamma function $\Gamma(\mathrm{x})$, defined by:

$$
\Gamma(x)=\int_{0}^{+\infty} t^{x-1} e^{-t} d t \text { and } \Gamma(1+x)=x \Gamma(x)
$$

\section{ESTIMATION OF THE POWER AND ENERGY PRODUCED BY A WIND TURBINE}

In this part, we will estimate the power produced by a wind turbine, using two methods.

\subsection{Method Based on the Calculation of the Usable Power}

This method allows computing the usable power $P_{u}$ obtained at the wind turbine output.

\subsubsection{Available Power Energy Density}

The average energy power available on a given location, per time unit and per area unit, due to the wind speed, is:

$$
<P>=\frac{1}{2} \rho<V^{3}>
$$

where $\rho=1.25 \mathrm{~kg} / \mathrm{m}^{3}$, is the air average density, under the conditions of temperature and atmospheric pressure, such as: $T=20^{\circ} \mathrm{C}$ and $P_{r a}=1$ atm.

The determination of the average cubic speed is according to the Weibull distribution and from the statistical study of the distribution of frequencies of average wind speeds; so, it's described by:

$$
<V^{3}>=c^{3} \Gamma\left(1+\frac{3}{k}\right)
$$

\subsubsection{Recoverable Wind Energy Potential (Betz Theorem)}

The available kinetic energy transported by the wind, representing the movement of a given mass of air, is converted into mechanical energy by using the blades of the propeller of wind, commonly called "wind turbine". The speed of wind downstream of the wind propeller, which must never be zero, leads to the fact that the wind power available is never entirely recovered at the helix [6].

Considering the limit of Betz (16/27), and replacing the air density by its mean, the maximum average power recoverable energy per unit area is given by:

$$
<P_{r}>=\frac{16}{27}<P>
$$

Or again:

$$
<P_{r}>=0.37<V^{3}>
$$

Finally, the average energy density recoverable over a year $\langle E\rangle$ is equal to:

$<E>=<P_{r}>\Delta t$

Such that, $\Delta t=24(365.25) \mathrm{h}$. Let in $\mathrm{kWh} / \mathrm{m}^{2}$ :

$<E>=3.24<V^{3}>$ 


\subsubsection{Usable Mean Wind Power}

Given that wind speed is variable and that the wind turbine is characterized by the respective speeds, the starting $V_{i}$, nominal $V_{n}$ and specific cut off $V_{s}$, the average usable wind turbine power density, $P_{u}$, is given by:

$$
<P_{u}>=\frac{1}{2} \rho<V_{u}^{3}>
$$

The usable speed $V_{u}$ is deduced from the curve representative of the Weibull distribution. It is between the limits of the wind turbine that are the starting speed $V_{d}$ and the stop $V_{s}$.

The average density of the usable power is given by the following system of Equations:

$$
<P_{u}>=\left\{\begin{array}{cc}
0 & \text { if } \quad V<V_{d} \\
\frac{1}{2} \rho<V_{u}{ }^{3}> & \text { if } V_{d} \leq V \leq V_{n} \\
\frac{1}{2} \rho V_{n}^{3} & \text { if } V_{n} \leq V \leq V_{s} \\
0 & \text { if } \quad V>V_{s}
\end{array}\right.
$$

After integration and using the normalized gamma function, we obtain the following Equation:

$$
<V_{u}^{3}>=V_{n}^{3}\left[e^{-\left(\frac{V_{n}}{c}\right)^{k}}-e^{-\left(\frac{V_{s}}{c}\right)^{k}}\right]+\overline{V^{3}}\left[\Gamma_{n}\left(\left(\frac{V_{n}}{c}\right)^{k},\left(1+\frac{3}{k}\right)\right)-\Gamma_{n}\left(\left(\frac{V_{d}}{c}\right)^{k},\left(1+\frac{3}{k}\right)\right)\right]
$$

with:

$$
\Gamma_{n}(x, a)=\Gamma(x, a) / \Gamma(x)
$$

\subsubsection{Useful Average Wind Power}

The avearge wind power really useful, $P_{e}$, is written:

$$
<P_{e}>=\eta<P_{u}>
$$

where $\eta$, is the machine efficiency provided by the manufacturer.

\subsection{Method Based on the Modeling of the Power Curve}

This method allows the estimation of power produced by a wind turbine by modeling the power curve of the latter.

\subsubsection{Modeling of a Wind Power Curve}

The power curve of a wind turbine is a performance specification supplied by the manufacturer. It represents the wind turbine output power depending on wind speeds. This curve is generally used to estimate the average energy production in a location, for a given wind profile [10]. The Figure 1 shows a typical curve of the power produced by the GAMESA G52-850 wind turbine.

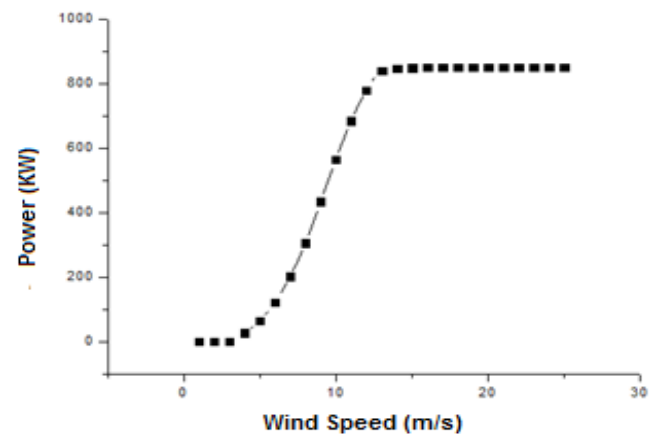

Figure 1. Power curve of the G52-850 wind turbine provided by the manufacturer [9] 
As can be noted, the curve of Figure 1 and the data in table 1 can be divided into three areas [15]:

a. Area 1: Corresponding to the minimum starting speed (Cut-in Wind Speed): This is the wind speed at which the turbine starts delivering a useful power associated with a usable electric power.

b. Area 2: Associated to the maximum speed, or the stop speed (Cut-out Wind Speed): This is the maximum acceptable wind speed. Beyond this, the mechanical strength of various components of the wind turbine is not ensured. In case of the excessive wind speed, the wind turbine is automatically stopped to preserve its integrity.

c. Area 3: Corresponding to the Rated power: This value is often equal to the maximum electric power that can be extracted from the wind turbine. It is a power that is never reached at the maximum acceptable wind speed. Indeed, shortly before reaching the speed of shutdown, in order to secure the equipment and minimize wear, devices are used to slow down the rotor speed, either dynamically or aerodynamically, which may significantly reduce wind turbine performance.

To model the power curve, there are two approaches; namely the application of a model power curve available in the literature or the use of real curves to which we apply an interpolation method [16]. We will adopt the last technique as a method to Lagrange polynomial interpolation. The typical curve of the wind turbine under test can be modeled by:

$$
P(V)=\left\{\begin{aligned}
0 & \text { if } V<V_{d} \\
L_{5}(V) & \text { if } V_{d} \leq V \leq V_{n} \\
P_{n} & \text { if } V_{n} \leq V \leq V_{s} \\
0 & \text { if } V>V_{s}
\end{aligned}\right.
$$

where $L_{5}(V)$ is a five-degree polynomial given by the following Equation:

$$
L_{5}(V)=a_{0}+a_{1} V^{1}+a_{2} V^{2}+a_{3} V^{3}+a_{4} V^{4}+a_{5} V^{5}
$$

\subsubsection{Power and Energy Produced by a Wind Turbine}

The average power generated by a wind turbine can be directly computed from the probability density, $f(V)$, using the following Equation:

$$
P_{g, \text { éol.moy. }}=\int_{V_{d}}^{V_{S}} P(V) f(V) d V
$$

The power generated by a wind turbine varies only between two speeds; startup and nominal ( $V_{n}$ and $V_{d}$ ), whereas it remains constant beyond $V_{n}$. So, the average power $P_{\text {g. éol. moy. }}$ can be estimated by:

$$
P_{g, \text { éol.moy. }}=\int_{V_{d}}^{V_{s}} L_{5}(V) f(V) d V+P_{n} \int_{V_{d}}^{V_{s}} f(V) d V
$$

According to the wind turbine power curve, the electrical energy produced by this latter during a period $T$, is calculated by the following relationship:

$$
E_{g, \text { éol.moy. }}=T P_{g, \text { éol. } m o y .}
$$

\section{RESULTS}

Hereinafter, we present the results of our study. First, we present the evolution of instantaneous and seasonal speed. Secondly, the wind rose will be exposed. After calculating Weibull parameters, we evaluate the power produced by a wind turbine of the wind farm under test.

\subsection{The Instantaneous Wind Speed Evolution}

The figure 2 below shows an example of the instantaneous wind speed profile. According to these measures, we note that the wind speed varies randomly. 


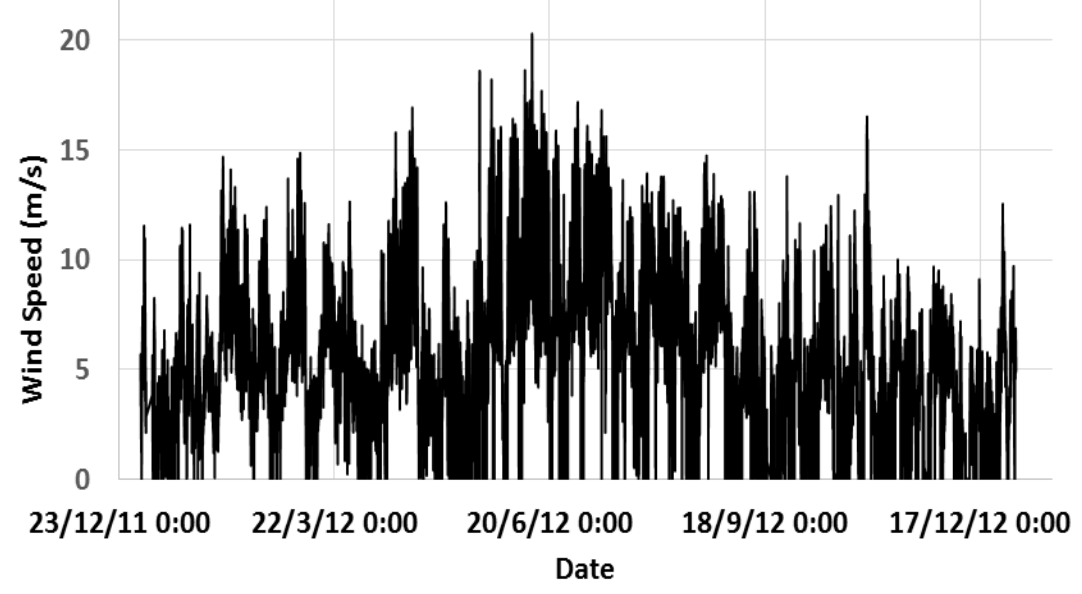

Figure 2. Evolution of instantaneous wind speed

\subsection{The Seasonal Wind Speed Evolution}

The seasonal or monthly wind speed variations, depends on the geographical location considered. Using the meteorological data for a series of wind parameters over a long period, we can characterize the monthly changes in the wind speed. Figure 3 shows a typical recording of these variations, spread on differents seasons of 2012 .

\subsection{Wind Rose}

Wind characteristics, deduced from meteorological data of the Amougdoul wind farm during 2012, are regrouped in monthly and daily files, depending on the wind sectors and direction. Using these data, we report the measurements on Figure 4 corresponding to the wind rose of wind farm under test.

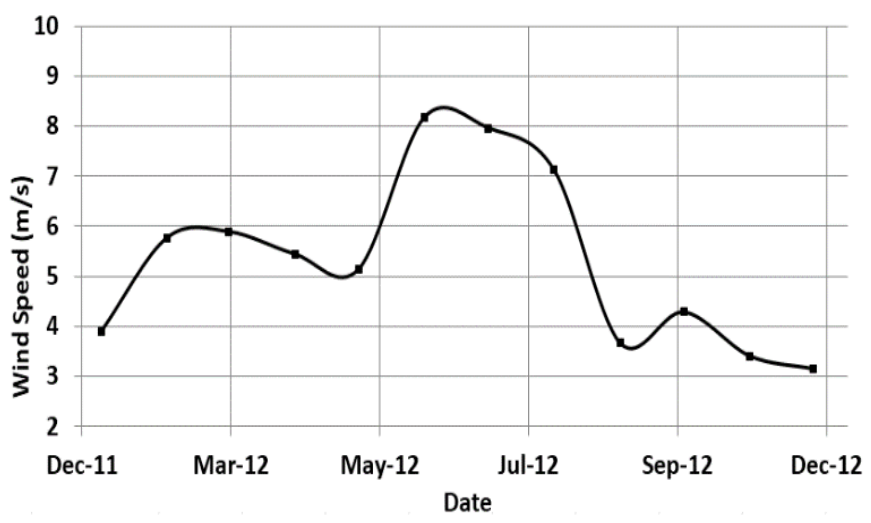

Figure 3. The average wind speed seasonal variation

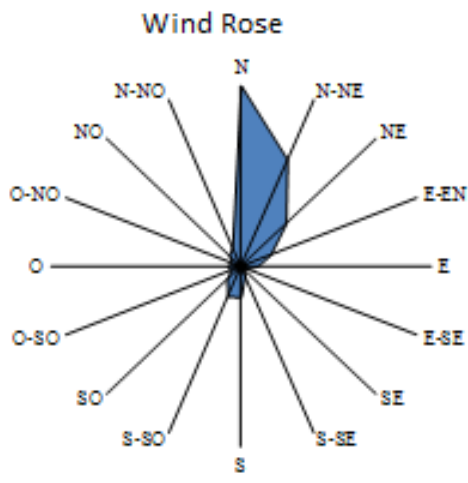

Figure 4. Wind rose of the Amougdoul wind park

The radius of each of the sixteen conical sectors in this figure 4 indicates the relative frequency of each wind direction in this wind farm. This wind rose provides information on the preferred wind directions and the magnitude of its average speed.

From this wind rose, concerning the site under test, we can deduce the predominant sectors, that is to say the direction in which the wind blows strongly and quite frequently, and the low dominance sectors corresponding to the directions where the winds blow slightly and less frequently. Regarding these sectors, Table 1 sums up the analysis of Figure 4.

From this table, we can see that the sectors with very strong dominance are the North, North/"North East" and North/East. However, the other sectors are at medium or even very low dominance. 
Table 1. Dispersion of the sectors dominance

\begin{tabular}{ccc}
\hline$\%$ & Direction & \\
\hline 31.45 & $\mathrm{~N}$ & \\
20.06 & N-NE & \\
10.56 & NE & \\
5.33 & E-EN & Predominant sectors \\
5.71 & S-SO & \\
5.33 & S-SO & \\
3.64 & N-NO & \\
3.26 & SO & \\
2.77 & E & Low sectors \\
2.75 & NO & \\
2.31 & O & \\
1.82 & O-SO & \\
1.79 & S-SE & \\
1.64 & O-NO & \\
1.05 & E-SE & \\
0.54 & SE & \\
\hline
\end{tabular}

\subsection{Calculation of Average Speed and Standard Deviation}

From the Equations (4) and (6), we can deduce the wind average speed of wind farm and its standard deviation; Let, $V_{m o y}=5.3529 \mathrm{~m} / \mathrm{s}$ and $\sigma=3.5835 \mathrm{~m} / \mathrm{s}$.

\subsection{Results of the Weibull Parameters}

To determine Weibull parameters, $c$ and $k$, from the statistical treatment of wind data, many methods can be used [13]. Among these techniques, we retain those of least squares (Ls) and those of the standard deviation and average speed $(\mathrm{Sd})$.

\subsection{Least Squares Technique (Ls)}

We apply below, the calculation procedure described above. After this treatment, Table 2 and Figure 5 summarize the results concerning the logarithms, $x_{i}$ and $y_{i}$, which we successfully have obtained.

After adjustment by linear regression of the curve, $y_{i}=f\left(x_{i}\right)$, we obtain the Equation of a line $y=a x+b$. From the regression coefficients a and $\mathrm{b}$, we deduce $k=1,619$ et $c=6,48 \mathrm{~m} / \mathrm{s}$.

This (Ls) method has two disadvantages:

- It does not apply to a zero speed, since $\operatorname{Ln}(V=0)$ is indefinite;

- It is not either applicable to the maximum speed $\operatorname{Ln}\left(1-F\left(V=V_{\max }\right)\right)=\operatorname{Ln}(0)$.

Table 2. The parameters calculation data

\begin{tabular}{ccccc}
\hline$y_{i}$ & $x_{i}$ & $\begin{array}{c}\text { Cumulative } \\
\text { frequency }\end{array}$ & Frequency [\%] & $\begin{array}{c}\text { Wind speed } \\
{[\mathrm{m} / \mathrm{s}]}\end{array}$ \\
\hline$-2,55522724$ & 0 & 0,0747345 & $5,51 \%$ & 1 \\
$-1,81838788$ & 0,693147 & 0,149803 & $7,51 \%$ & 2 \\
$-1,28936299$ & 1,098612 & 0,2407667 & $9,10 \%$ & 3 \\
$-0,93742217$ & 1,386294 & 0,32405 & $8,33 \%$ & 4 \\
$-0,62458789$ & 1,609438 & 0,414613 & $9,06 \%$ & 5 \\
$-0,32428708$ & 1,791759 & 0,5147265 & $10,01 \%$ & 6 \\
$-0,09522324$ & 1,94591 & 0,5971415 & $8,24 \%$ & 7 \\
0,11614137 & 2,079442 & 0,6747479 & $7,76 \%$ & 8 \\
0,31610477 & 2,197225 & 0,7463434 & $7,16 \%$ & 9 \\
0,50892467 & 2,302585 & 0,8105256 & $6,42 \%$ & 11 \\
0,70365853 & 2,397895 & 0,8674948 & $5,70 \%$ & 12 \\
0,87495355 & 2,484907 & 0,9091698 & $4,17 \%$ & 13 \\
1,05924056 & 2,564949 & 0,9440994 & $3,49 \%$ & 14 \\
1,26115748 & 2,639057 & 0,9706806 & $2,66 \%$ & 15 \\
1,49272832 & 2,70805 & 0,9883123 & $1,76 \%$ & 16 \\
1,68266929 & 2,772589 & 0,9953917 & $0,71 \%$ & 17 \\
1,80148796 & 2,833213 & 0,9976625 & $0,23 \%$ & 18 \\
1,96418461 & 2,890372 & 0,9991986 & $0,15 \%$ & 19 \\
2,08001212 & 2,944439 & 0,9996661 & $0,05 \%$ & \\
\hline
\end{tabular}




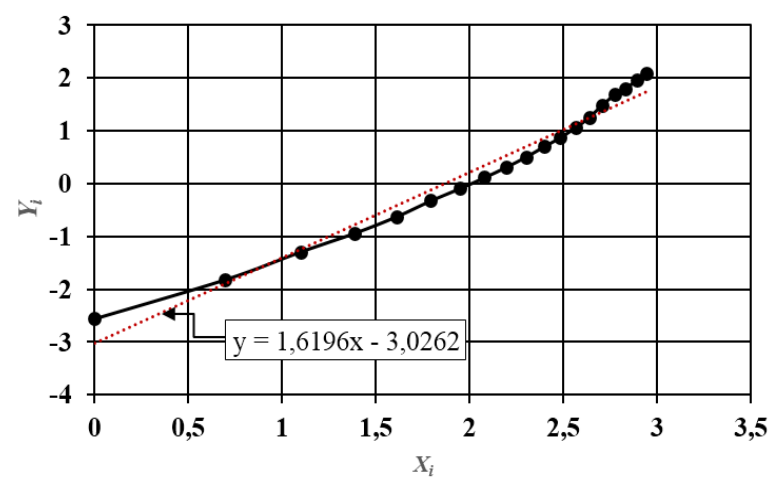

Figure 5. Curve $y_{i}=f\left(x_{i}\right)$

\subsection{Technique of the Standard Deviation and Average Speed (Sd)}

To exploit this ( $\mathrm{Sd}$ ) method, from Equations 8 and 9, we deduce the Weibull parameters, $k$ and $c$, Let:

$$
k=1.54, \operatorname{so} \Gamma\left(1+\frac{1}{k}\right)=0.9 \text { and of } \quad c=5.95 \mathrm{~m} / \mathrm{s}
$$

\subsection{Comparison between the Two Methods Ls and Sd}

Following the above described techniques, Table 3 below summarizes the results obtained for the parameters, $k$ and $c$. This table contains the RMBE (Relative Mean (Bias) Error) term corresponding to the mean relative error. Indeed, the evaluation of the precision of these two methods $L s$ and $S d$ is performed by comparing the values of $R M B E$, calculated by [11].

$$
\operatorname{RMBE}(\%)=100 \frac{\frac{1}{N} \sum_{i=1}^{N}\left(y_{i}-y_{i w}\right)}{\frac{1}{N} \sum_{i=1}^{N} y_{i w}}
$$

with:

$y_{i w}: i^{\text {th }}$ Weibull distribution data

$y_{i}: i^{\text {th }}$ real data

$N$ :number of data

Table 3. Comparison of Weibull parameters

\begin{tabular}{cccl}
\hline$R M B E(\%)$ & $c(\mathrm{~m} / \mathrm{s})$ & $k$ & \\
\hline 1,35 & 6,48 & 1,619 & Least Squares (Ls) \\
1,96 & 5,95 & 1,54 & The standard deviation and average speed (Sd) \\
\hline
\end{tabular}

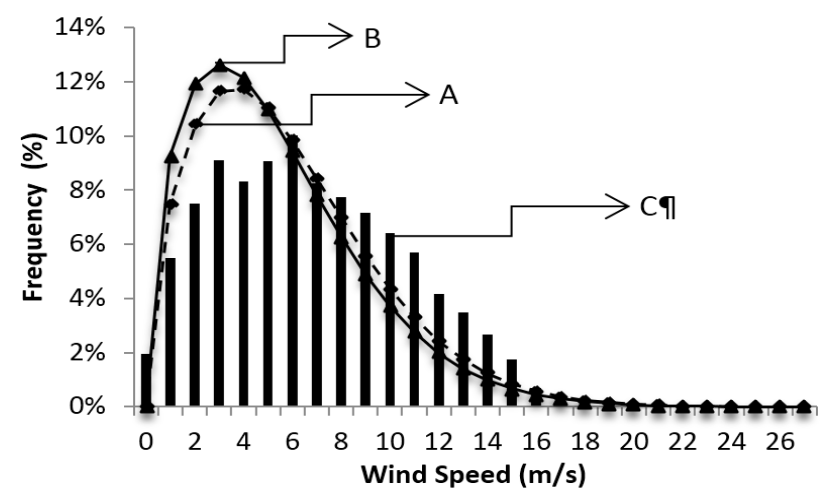

Figure 6. Distribution of the average wind speed 
According to the results of this Table 3, we also note that the (Ls) least squares method is one that gives satisfactory results, since it corresponds to the lowest $R M B E$ error.

This finding is also visible on the curves of the Weibull distribution presented on figure 6 obtained by using values, $k$ and $c$. These are determined from the two methods; Ls, represented by curve "A" and Sd, represented by the "B" curve. Indeed, we notice on these curves, between the machine limits $\left(V_{d}=4 \mathrm{~m} / \mathrm{s}\right.$, $V_{s}=25 \mathrm{~m} / \mathrm{s}$ ), that the "A" curve is closer to the frequency diagram "C".

Following these two reasons, in the remainder of our work we will choose the Weibull parameters determined by the least squares method Ls; Let $k=1.619$ and $c=6.48 \mathrm{~m} / \mathrm{s}$.

\subsection{Power Curve of Wind Turbine GAMESA G52-850}

From the databases of measurements recorded in the Amougdoul wind farm, both in terms of the weather information and the active power delivered by wind turbine of site, we can represent according to the wind speed, as shown in Figure 7, the changes in recoverable power by one of wind turbine.

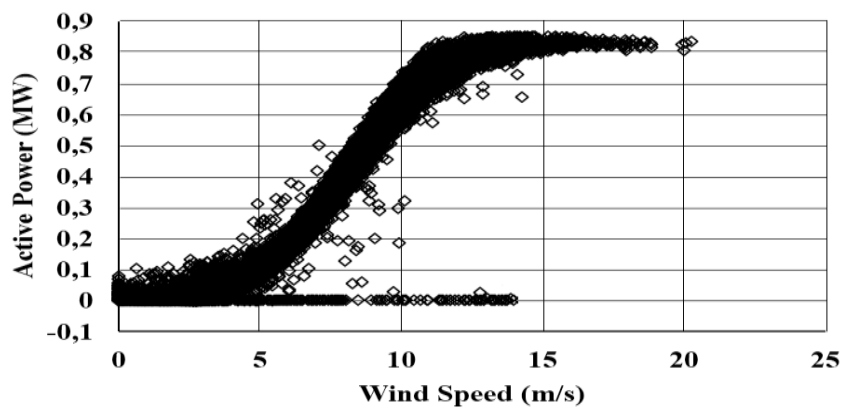

Figure 7. Recoverable power evolution of an aerogenerator

In the case of aerogenerators G52-850, used in the Amougdoul wind farm, the minimum start speed is $4 \mathrm{~m} / \mathrm{s}$ (around $14 \mathrm{~km} / \mathrm{h})$, while the stop speed is $25 \mathrm{~m} / \mathrm{s}(\approx 90 \mathrm{~km} / \mathrm{h})$.

We note that this evolution of the power measured at one of the aerogenerators, has typically the same shape as the power curve provided by the manufacturer. Table 4 shows the aerogenerator G52-850 characteristics [9]

Table 4. The aerogenerator G52-850 characteristics [9]

\begin{tabular}{cccc}
\hline$P(\mathrm{~kW})$ & $V(\mathrm{~m} / \mathrm{s})$ & $P(\mathrm{~kW})$ & $V(\mathrm{~m} / \mathrm{s})$ \\
\hline 684.6 & 11 & 0.0 & 1 \\
779.9 & 12 & 0.0 & 2 \\
840.6 & 13 & 0.0 & 3 \\
848.0 & 14 & 27.9 & 4 \\
849.0 & 15 & 65.2 & 5 \\
850.0 & 16 & 123.1 & 6 \\
850.0 & 17 & 203.0 & 7 \\
850.0 & 18 & 307.0 & 8 \\
850.0 & 19 & 435.3 & 9 \\
850.0 & 20 à 25 & 564.5 & 10 \\
\hline
\end{tabular}

\subsection{Modeling the Curve of Power Generated by Wind Turbine}

The modeling of the power curve produced by a wind turbine requires the evaluation of the Lagrange polynomial, ie the determination of the $a_{i}$ coefficients associated to the latter. In the objective of this modeling, we report in Table 5 the values of these coefficients $a_{i}$, concerning the Lagrange polynomial, which are determined using the program that we have developed under Matlab. Figure 8 illustrates the flow chart associated with this program.

Table 5. The Lagrange polynomial coefficients

\begin{tabular}{cccccc}
\hline $\boldsymbol{a}_{\mathbf{0}}$ & $\boldsymbol{a}_{\mathbf{1}}$ & $\boldsymbol{a}_{\mathbf{2}}$ & $\boldsymbol{a}_{\mathbf{3}}$ & $\boldsymbol{a}_{\mathbf{4}}$ & $\boldsymbol{a}_{\mathbf{5}}$ \\
\hline-368770 & 288020 & -86300 & 12400 & -700 & 10 \\
\hline
\end{tabular}

Evaluation of the Energy Performance of the Amougdoul Wind Farm, Morocco (Asma Ezzaidi) 


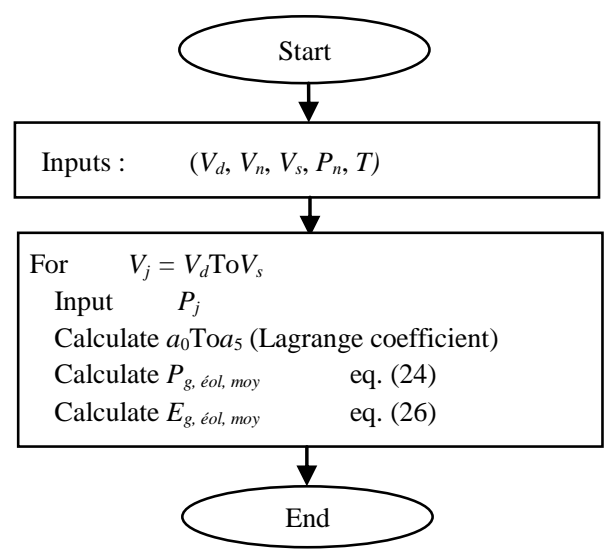

Figure 8. The program flow chart developed under Matlab

Starting from the calculated values of the Lagrange polynomial coefficients, $a_{i}$, we have plotted, as illustrated in Figure 9, the comparison between the curves "A" associated to the simulated produced power, and "B" that concerning actual power supplied by the manufacturer.

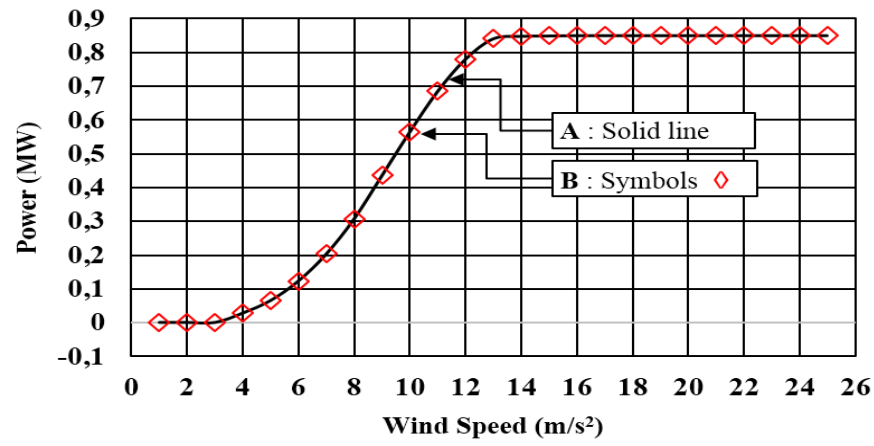

Figure 9. Comparison between the simulated power curve and the one provided by the manufacturer

We note that the simulated power curve is perfectly correlated with the actual power curve of the manufacturer, which validates the approach used for our simulation.

\subsection{Estimate of the Power and Energy Produced by a Wind Turbine}

In this section, we will estimate the power produced by the G58-850 aerogenerator, using the two methods listed in section V.

\subsubsection{Method Based on Calculating the Useful Power}

In this case, we calculate the energy power available $P$ then, the recoverable maximum average power, $P_{r}$ then, the wind power density usable, $P_{u}$ and finally the useful average power density $P_{e}$, using respectively the Equations (10) (12), (16) and (20). Consequently, Table 6 summarizes the various powers calculated for the aerogenerator under test, and their percentages relative to the available energy power $P$.

Table 6. Power produced by an aerogenerator

\begin{tabular}{cccc}
\hline Reported to $P(\%)$ & $\begin{array}{c}\text { Corresponding } \\
\text { power }(\mathrm{W})\end{array}$ & $\begin{array}{c}\text { Power } \\
\text { density }\left(\mathrm{W} / \mathrm{m}^{2}\right)\end{array}$ & \\
\hline 100.00 & 497625.75 & 234.44 & $P$ \\
59.26 & 294889.33 & 138.93 & $P_{r}$ \\
27.87 & 138706.02 & 65.35 & $P_{u}$ \\
27.04 & 134544.84 & 63.39 & $P_{e}$ \\
\hline
\end{tabular}


We note that the mean useful wind power, $P_{e}$ represents only $27.04 \%$ of the energy power available. This indicates that all of the energy captured by the wind turbine is not converted into electrical energy by the aerogenerator.

From this Table 6 and the relation (14), we calculate the average energy density recoverable over a year, representing the annual potential to mean recoverable. This corresponds to a value of $1.21 \mathrm{MWh} / \mathrm{m}^{2} /$ year.

\subsubsection{Method Based on the Modeling of the Power Curve}

In this method, we use Equation (24) and the program developed in Matlab (Fig. 8) for calculating the average power, $P_{\text {g. éol. moy, }}$ generated by a wind turbine. This leads us to Table 7 giving $P_{g \text {. éol. moy. }}$ as well as its relative percentage to the available energetic power $P$.

Table 7. Power produced by an aerogenerator

\begin{tabular}{ccl}
\hline Reported to $P(\%)$ & $\begin{array}{c}\text { Corresponding } \\
\text { power }(\mathrm{W})\end{array}$ & \\
\hline 100.00 & 497625.75 & $P$ \\
39.02 & 194190.00 & $P_{\text {g.éol. moy. }}$ \\
\hline
\end{tabular}

We note that the average power generated by a wind turbine is only $39.02 \%$ of the energy power available; this also shows that not all energy captured by the wind turbine is converted into electrical energy by the aerogenerator. We report that this value; $39.02 \%$, evaluated by this second method is quite similar to that of other authors [6].

From Table 7 and Equation (25), we also calculate the value of the electrical energy produced during one year by the wind turbine. So, this corresponds to $1701.1 \mathrm{MWh} / \mathrm{year}$ equivalents to $0.8 \mathrm{MWh} / \mathrm{m}^{2} /$ year of the power density.

\section{CONCLUSION}

In this paper, we have estimated and modeled the wind resources of the Amougdoul wind farm, located in the south-west of Morocco. According to this study, we have found that this site features a wind potential which is relatively average, since the annual average wind speed does not exceed $5.35 \mathrm{~m} / \mathrm{s}$ and because of a shape parameter and scale that have the respective values; 1.619 and $6.48 \mathrm{~m} / \mathrm{s}$. These parameters are calculated from the least squares method (Ls), as it represents a minimum value of the relative mean (Bias) error (RMBE) compared to the method of standard deviation and average speed (Sd).

Using the method based on the calculation of the useful power and that based on the modeling of the power curve, we have estimated the electric power generated by the G58-850 wind turbine; which is $134.5 \mathrm{~kW}$ and $194.19 \mathrm{~kW}$ respectively, corresponding to a $27 \%$ and $39 \%$ of wind power available, confirming that the conversion efficiency does not exceed $40 \%$. In addition, the method based on modeling of the power curve is better correlated with reality, since it's based on the experimental curve modeling of the aerogenerator power under test.

\section{ACKNOWLEDGEMENTS}

We thank Mr. LAARAJ Abderrahim of ONEE (National Office of Electricity and potable water) and responsible of the Amougdoul wind farm, for kindly providing us with the data necessary to carry out this work.

\section{REFERENCES}

[1] R. Naveen Kumar, J.Baskaran,"Energy Management system for Hybrid RES with Hybrid Cascaded Multilevel inverter", International Journal of Electrical and Computer Engineering (IJECE), Vol. 4, No. 1, pp. 24, Feb 2014.

[2] J.B. Fulzele, SubrotoDutt,"Optimium Planning of Hybrid Renewable Energy System Using HOMER", International Journal of Electrical and Computer Engineering (IJECE), Vol. 2, No. 1, pp. 68, Feb2012.

[3] Jian-Ping Zhang, Hao-Zhong Cheng, Zhen-Dong Wan, Liang-Zhong Yao, "Joint Optimization between Power Sources and Transmission Expansion Planning Considering Integration of Large Scale Wind Power", International Review of Electrical Engineering (IREE), Vol 8, No 6, pp. 1815-1822, 2013.

[4] S.M. Mohseni-Mansur, Hamidreza Abdollahi-Mansoorkhani, Esmaeil Abedini-Duki, Abolfazl Pirayesh, "A Multi Objective Framework for Solving Economic Load Dispatch Problem Including Stochastic Nature of Wind Power", International Review of Electrical Engineering (IREE), Vol 8, No 1, pp. 362-378, 2013. 
[5] Naim Cherfia, Djallel Kerdoun, "Wind Energy Conversion Systems Based On a DFIG Controlled By Indirect Vector Using PWM and SVM", International Journal of Electrical and Computer Engineering (IJECE), Vol. 6, No. 2, pp. 549, April 2016.

[6] N. Kasbadjimerzouk, "Evaluation du gisement énergétique éolien - Contribution à la détermination du profil vertical de la vitesse du vent en Algérie", Thèse de Doctorat, Université Abou-BekrBelkaid de Tlemcen, Algérie, 2006.

[7] H. Faida, J. Saadi, M. Khaider, S. El Alami et M. Monkade, "Etude et analyse des données du vent en vue de dimensionner un système de production d'énergie éolienne cas d'un site au nord du Maroc", Revue des Energies Renouvelables, Vol. 13, No 3, pp. 477-483, 2010.

[8] E.G. Pavia, J.J. O'Brien, "Weibull Statistics of Wind Speed Over the Ocean", Journal of Climate and Applied Meteorology, Vol. 25, pp. 1324-1332, 1986.

[9] Catalogue Gamesa Eolica, "Description des aérogénérateurs G52/G58_850kW", pp. 3-9, 28/11/2001.

[10] Mohammed Benchrif, "Modélisation de systèmes énergétiques photovoltaïques et éoliens intégration dans un système hybride basse tension", Thèse de Doctorat, Université Abou-Bekr Belkaid, Tlemcem, Algérie, http://dspace.univ-tlemcen.dz/handle/112/4178, 2014.

[11] Ciprian-MirceaNemeş, "Statistical Analysis of Wind Speed Profile: A Case Study from Iasi Region, Romania", International Journal of Energy Engineering (IJEE), Vol. 3, Issue 6, pp. 261-268, 2013

[12] J.P. Hennessey, "A comparison of the Weibull and Rayleigh distributions for estimating wind power potential", Wind Engin., 2, pp. 156-164, 1978.

[13] C.G. Justus, and A. Mikhail, "Height variation of wind speed and wind distribution statistics", Geophys. Res. Lett., 3, pp. 261-264, 1976

[14] D. Weisser, "A wind energy analysis of Grenada: an estimation using the Weibull density function", Renewable Energy, 28, pp. 1803-1812, 2003.

[15] Saïdou Madougou, "Etude du potentiel éolien du Jet Nocturne dans la zone Sahélienne à partir des observations de radars profileurs de vent", Thèse de Doctorat, Université Toulouse 3 Paul Sabatier, France, 2010.

[16] Ludmil Stoyanov, "Etude de différentes structures de systèmes hybrides à sources d'énergie renouvelables", Thèse de Doctorat, Université de Corse Pasquale Paoli, en cotutelle avec l'Université Technique de Sofia, 2011.

\section{BIOGRAPHIES OF AUTHORS}

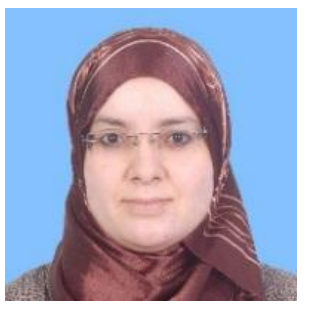

Asma Ezzaidi Electromechanical Engineer (2009) with a high school certificate (2004) in physics in high school LalaMeryam Agadir Morocco, and preparatory classes in Agadir Morocco, then the national school of the mineral industry, Rabat Morocco. Her research, in the context of national doctoral thesis, focuses on the thematic of renewable Energies. The doctoral investigations took place in the Resarch Team in Advanced Technologies and Engineering of Renewable Energies (ERTAIER) Agadir, Morocco

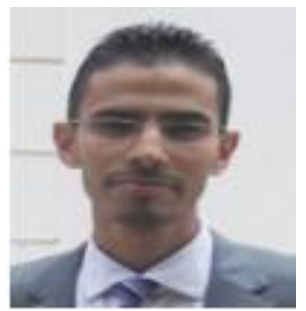

Mustapha Elyaqouti was born in Agadir, Morocco, in 1984. He received the technical University degree (DUT) in Electrical Engineering from the High School of Technologies of Agadir (EST Agadir), in 2006. He received his B.Sc degree in physics and a post graduate degree in Materials Engineering and energetic environment from IbnZohr University, in 2010 and 2012. His research, in the context of national doctoral thesis, focuses on the thematic of Renewable Energies. The doctoral investigation took place in the Research Team in advanced Technologies and Engineering of Renewable Energies (ERTAIER) Agadir Morocco.

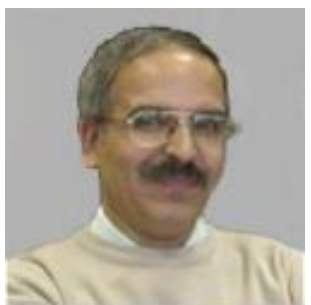

Lahoussine Bouhouch Professor of higher education at the ESTA (High School of Technologies of Agadir), Ibn Zohr University, Agadir, Morocco. PhD Electrical Engineering at the Nancy I University, France in 1988 and state doctorate in Electrical Engineering in 2007. Responsible of the research team ERTAIER (Research Team in Advanced Technologies and Engineering of Renewable Energies). His research focuses on topics related to renewable energy, instrumentation and electromagnetic compatibility (EMC 


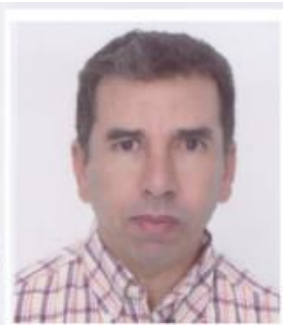

Ahmed Ihlal was born and brought up in Morocco. He studied Physics and Chemistry and holds, in 1984, his BSc degree (LicenceEs-Sciences Physique) in Solid State Physics from the University Mohamed V, Rabat - Morocco. He then joined Paris VII University - France, where he got, in 1985, a MSc. degree (DEA: Diplome des Etudes Approfondies) in Solar Energy. He pursued his research on the studies and got, in 1988, a PhD degree from the University of Caen Basse Normandie - France. Dr. A. Ihlal started his teaching career on I988 as Assistant Professor in the faculty of Science at University IbnZohr. Then he holds a "Doctoratd'Etat" thesis in 1995. $\mathrm{He}$ is currently Full Professor in Faculty of Sciences, University IbnZohr, Agadir - Morocco. He is head of the group working on developing cost effective processes for the fabrication of CIGS and CZTS absorber layers, buffer layers and TCOs. He is working on PV and CSP systems as well. He has published 60 scientific papers, and acted as a referee for numerous international journals. He has contributed to the organization of numerous national and international conferences and was a member of scientific committees for several international conferences. $\mathrm{He}$ is supervising PhD, MSc as well as BSc students in the field of PV and CSP. He is an expert of the CNRST in the field of renewable energies. 